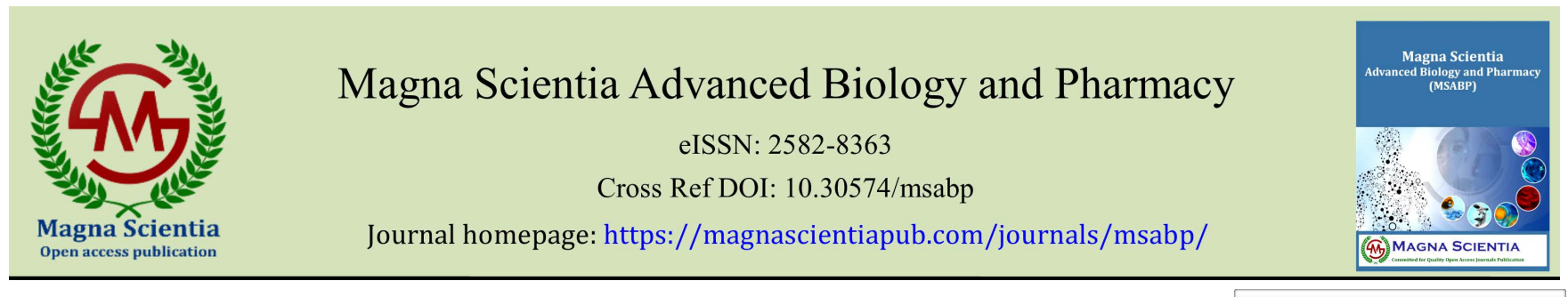

(REVIEW ARTICLE)

\title{
A conflict with prescription shoppers
}

\author{
Basem Abbas Al Ubaidi * \\ Ministry of Health, Head of the primary care research team, Arabian Gulf University (AGU), Kingdom of Bahrain.
}

Magna Scientia Advanced Biology and Pharmacy, 2021, 03(01), 045-048

Publication history: Received on 25 March 2021; revised on 03 May 2021; accepted on 06 May 2021

Article DOI: https://doi.org/10.30574/msabp.2021.3.1.0017

\begin{abstract}
The physician should be familiar with early diagnosis and dealing with patients who seek nonmedical drug prescriptions. It is a dilemma, and it may create a problem in health care practice in unequipped physicians. The common illegal drugs requested by 'prescription shoppers' are opioids and benzodiazepines.
\end{abstract}

Keywords: Substance-related disorders; Street drugs; Drug prescriptions; General practice

\section{Introduction}

Pandemic drug abuse is an increasing problem in all countries [1]. The definition of drug abuse is an uncontrolled urge to drug-seeking and suffering from many withdrawal symptoms [2]. Most physicians are not well prepared for recognizing and dealing with 'prescription shoppers.' The usual clinical scenario may end in a conflict escalation. Most of the requesting drugs are benzodiazepine, sedatives, opioids, antipsychotics, and psych stimulants $[3,4]$. The drug abuse method has many ways, either in inhalation, tablet, smoking, or injection methods. When the drug abuser needs their illegal medicine, they will get it either from outside (street drugs) or get it from inside (health services) [5].

Drug abuse is a severe public health problem and has many adverse consequences. It will create a social problem, damage interpersonal relationships, and interrupt family relationships. Also, they will have legal and or police and or work problems on the prolonged drug abuse run. The psychological problems of drug abuse are many, such as anxiety, depression, and aggressive behavior. Consequently, they will have traffic accidents, withdrawal symptoms, and an increase in HIV/AIDS incidence [5]. The physician should equip with many necessary skills to deal with drug shoppers. The physician should know how and when to say 'No.' The physician should follow the international guideline for drug abuse $[6,7]$. The prevalence rate of drug abuse is $9 \%$ of the population, and they had at least one previous experience with an illegal drug [8].

The physician needs to introduce himself and establish patient rapport. The physician should not be judgmental and avoid patient confrontational. The physician needs to use a brief screening questionnaire that detects the early history of drug/substance abuse (e.g., Alcohol, tobacco, nonmedical prescription drug, and illicit drugs) [10-11].

The warning signs that the physician raises suspicions of drug shoppers are many, such as late appointments, exaggerated symptoms, copy-paste textbook- symptoms. Also, they are presented with vague symptoms or providing an old medical report. Similarly, they claimed that they have an allergy to many medications. They insist on illegal drugs, and they are claiming in many ways, such as the drugs were lost, forgotten, stolen, or damaged. They claimed that their treating physician is unavailable or they have arrived from travel [12].

\footnotetext{
${ }^{*}$ Corresponding author: Basem Abbas Al Ubaidi

Ministry of Health, Head of the primary care research team Arabian Gulf University (AGU), Kingdom of Bahrain. 
The patient will use many behaviors, such as manipulative, aggressive, threatening, unnecessary praising, or even insisting on the drug [13]. The causes of the 'prescription shoppers' are many, such as ecstasy feelings, decreasing patient anxiety, and or masking depression symptoms [14]. The drug abuser patients are trying to search for special physician characters, such as untrained registrars, female physicians, new or overseas physicians. The drug abuse patient will try many methods to convince their physicians, either by revealing tall stories or having an urgent appeal, or using a bullying manner. [14].

\section{Warning signs for drug abuse}

Physical warning signs of drug abuse include congested red eyes, dilated or constricted pupils, changes in appetite, and sleep patterns. Moreover, they will have weight changes, appearance alterations, and neglect their personal hygiene. Besides, they may have tremors, slurred speech, or impairment in their movement coordination.

Behavioral signs of drug abuse include decrease work and or school performance, increase incidence of financial deficit, borrowing from others, or even indulging in robbery and or troublemaker. Likewise, they became a person with more secrets or having suspicious behaviors. The drug abuser will frequently change their friends, their jobs, and their residents

Psychological signs of drug abuse are many, such as personality disorder, easily irritability, anger outbursts, and mood swings. Moreover, they will have frequent uncontrolled agitation, hyperactivity, lack of motivation, lethargy, anxiety, and paranoid thinking. Drug abusers increase the incidence of depression, anxiety, and unstable patients. Drug administration, such as smoking or injecting methods, may increase its addictive potential [15].

\subsection{Vulnerability factors for drug addiction [16]}

The typical drug abuse risk factors are many, such as hereditary factors, psychosocial problems, personality disorders, and emotional or traumatic problems.

\subsection{What should a physician do when drug abuse is suspected? [17]}

The physician should be staying calm, non-judgmental, and not showing any shock or aversion reaction. Instead, the physician should be showing a supportive consultation in private clinics. The physician needs to listen attentively and gather important vital data (What happened? Where did it happen? When did it happen? Who is the supposed abuser?)

\subsection{Strategies dealing with prescription shoppers [18]}

The answer to the prescription shoppers is either clear, respectable 'NO' with short physician explanation (e.g., "It is my choice,' 'it is clinic policy.'). Alternatively, the physician can close the subject by putting a unique character; No addiction drugs will prescribe to new patients.

Some physicians prefer to prescribe many pills to take part in the treatment plan with their patients and set the ground rules for the future prescribing step-wise plan [6, 7]. However, some GPs can be so innocent or trusting and may not recognize the patient's manipulative and twisted ways of getting their drugs [11]. The physician should concentrate on their insight and not obey the patient's substance request [11].

The majority of sickle cell patients may have a drug abuse history. They may have many sickle cell crises experience that needs potent pain-killer sedatives. Potent sedatives are either will create drug diversity, adverse effects, or physically dependent addiction. Sicklier patients will eventually ask for dose increment because of physiological opioid tolerance and its interference on the pain aggravating [19-20].

\section{The National Institute on Drug Abuse (NIDA) [21, 22]}

The use of a brief NIDA Quick Screen test consists of four steps.

Step 1: Ask about last year's drug use or abuse within the previous year? (Prescription or illegal drugs).

The answers are rated five scaling rates (Never, once or twice, monthly, weekly, daily, or almost daily).

Step 2: Ask about lifetime drug use; how often has drug abuse in a lifetime? (Cannabis, cocaine, stimulants drugs, methamphetamine, inhalants, sedatives, sleeping pills, hallucinogens, street opioids, and prescribed opioids). 
Step 3: The physician should determine the risk scoring level. It will be either low-risk or intermediate-risk, or highrisk group.

Step 4: Then, the physician should use the Four A's intervention:

Advise all patients to quit their drug abuse.

Assess patient's readiness to quit their drug abuse.

Assist the patients in making their future changes.

Arrange treatment-plan or appropriate follow-up care.

The physicians should be careful about their voice tone and being non-judgmental or confrontational. The physicians should show their patient's interests, acknowledge the patient's situation, and focus on their patient confidentiality. Since drug abuse may lead to impaired patients' judgment, the physician should also be screening for transmitted sexual diseases (TSDs). The physician should evaluate the patient for any suspected psychiatric disorders.

\section{Conclusion}

The physician should have proper training on how to suspect and how to deal with drug seekers. The physician should say 'NO' to drug abusers when their requests are illegal. Refer patient to drug addict clinics for further evaluation and management. The use of pain guidelines is essential in every clinic.

\section{References}

[1] Kuehn, B. M. (2007). Prescription drug abuse rises globally. JAMA, 297(12), 1306-1306.

[2] Banta-Green, C. J., Merrill, J. O., Doyle, S. R., Boudreau, D. M., \& Calsyn, D. A. (2009). Opioid use behaviors, mental health, and pain-development of a typology of chronic pain patients. Drug and alcohol dependence, 104(1-2), $34-42$.

[3] Pagliaro, L. A., \& Pagliaro, A. M. (2019). Child and adolescent drug and substance abuse: A comprehensive reference guide. Routledge.

[4] Hulme, S., Bright, D., \& Nielsen, S. (2018). The source and diversion of pharmaceutical drugs for nonmedical use: a systematic review and meta-analysis. Drug and alcohol dependence, 186, 242-256.

[5] Devlin, R. J., \& Henry, J. A. (2008). Clinical review: Major consequences of illicit drug consumption. Critical Care, 12(1), 1-7.

[6] Si Hulse, G. K., Khong, E., \& Sim, M. G. (2004). Acute pain and opioid-seeking behavior. Australian family physician, $33(12)$.

[7] Carr, N. (1998). 'I just want some Valium, Doc'. Australian family physician, 27(9), 817-821.

[8] Abuse, S. (2009). Mental Health Services Administration (2006) Results from the 2005 National Survey on drug use and health: national findings. National Survey on Drug Use \& Health Series H-34, Department of Health and Human Services Publication No. SMA 08, 4343.

[9] Portenoy, R. K., Dole, V., Joseph, H., Lowinson, J., Rice, C., Segal, S., \& Richman, B. L. (1997). Pain management and chemical dependency: Evolving perspectives. JAMA, 278(7), 592-593.

[10] Leong, M., Murnion, B., \& Haber, P. S. (2009). Examination of opioid prescribing in Australia from 1992 to 2007. Internal medicine journal, 39(10), 676-681.

[11] Monheit, B. (2010). Prescription drug misuse. Australian family physician, 39(8).

[12] Australia, M. (2009). Medicare Australia annual report 2007-2008. Canberra, Australia: Medicare Australia.

[13] Martyres, R. F., Clode, D., \& Burns, J. M. (2004). Seeking drugs or seeking help? Escalating "doctor shopping" by young heroin users before the fatal overdose. Medical Journal of Australia, 180(5), 211-214.

[14] Jansen, C., Monheit, B., Grinzi, P., \& Parker, R. (2005). Addiction medicine training for general practice registrars. Australian family physician, 34(12 Suppl). 
[15] Noble, M., Treadwell, J. R., Tregear, S. J., Coates, V. H., Wiffen, P. J., Akafomo, C., ... \& Chou, R. (2010). Long-term opioid management for chronic noncancer pain. Cochrane database of systematic reviews, (1).

[16] Erickson, C. K. (2011). Addiction essentials: the Go-to guide for clinicians and patients (Go-to guides for mental health). WW Norton \& Company.

[17] DuPen, A., Shen, D., \& Ersek, M. (2007). Mechanisms of opioid-induced tolerance and hyperalgesia. Pain Management Nursing, 8(3), 113-121.

[18] Angst, M. S., \& Clark, J. D. (2006). Opioid-induced hyperalgesia: a systematic qualitative review. The Journal of the American Society of Anesthesiologists, 104(3), 570-587.

[19] Helping Alcoholics Quit: A Guide for Clinicians. https://pubs.niaaa.nih.gov/publications/Practitioner/CliniciansGuide2005/clinicians guide.htm.

[20] "Helping Smokers Quit: A Guide for Clinicians" http://www.ahrq.gov/clinic/tobacco/clinhlpsmksqt.htm.

[21] Rossi, P., Lorenzo, C. D., Faroni, J. A., Cesarino, F., \& Nappi, G. (2006). Advice alone vs. structured detoxification programs for medication overuse headache: a prospective, randomized, open-label trial in transformed migraine patients with low medical needs. Cephalalgia, 26(9), 1097-1105.

[22] Vicens, C., Fiol, F., Llobera, J., Campoamor, F., Mateu, C., Alegret, S., \& Socías, I. (2006). Withdrawal from long-term benzodiazepine use: a randomized trial in family practice. British journal of general practice, 56(533), 958-963. 